\title{
STRATEGI PENGEMBANGAN POTENSI USAHA MIKRO, KECIL, DAN MENENGAH KERAJINAN TANGAN KISO "JAGO ABADI" DI DESA KEMIRI, KABUPATEN BANYUMAS
}

\author{
Muflih Nurriza Pahlawi*, Abu Dharin \\ UIN Prof KH. Saifuddin Zuhri Purwokerto \\ Corresponding Author*: muflihrezpector@gmail.com
}

\begin{abstract}
Micro, Small and Medium Enterprises (MSMEs) are an inseparable part of the national business world. The existence of MSMEs is something that is quite vital in improving the economy of the Indonesian people in various regions. This study aims to analyze the development strategy of the Kiso "Jago Abadi" handicraft SMEs in Kemiri Village, Banyumas Regency. This study uses a qualitative research method that involves actors as servants in the research subject, then participatively identifies problems and designs empowerment models for development in the form of work programs that can be done. The strategy applied is to design the programs needed for MSMEs as capital for strengthening and knowledge for MSME actors who are involved in it. The way that can be applied is by continuously developing the uniqueness of handicraft products, expanding market reach, always maintaining and improving product quality, and consistently promoting and maintaining the production of Kiso "Jago Abadi" handicrafts. The result of this service is the discovery of more optimal and efficient results in the production and marketing process of Kiso "Jago Abadi" handicrafts. The strategy for developing the potential of micro, small, and medium-sized handicrafts Kiso "Jago Abadi" in Kemiri village, Banyumas district can achieve maximum results. The result of this service is the discovery of more optimal and efficient results in the production and marketing process of Kiso "Jago Abadi" handicrafts. The strategy for developing the potential of micro, small, and medium-sized handicrafts Kiso "Jago Abadi" in Kemiri village, Banyumas district can achieve maximum results. The result of this service is the discovery of more optimal and efficient results in the production and marketing process of Kiso "Jago Abadi" handicrafts. The strategy for developing the potential of micro, small, and medium-sized handicrafts Kiso "Jago Abadi" in Kemiri village, Banyumas district can achieve maximum results.
\end{abstract}

Keywords: Strategy, Development, UMKM, Kiso "Jago Abadi"

\begin{abstract}
Abstrak
Usaha Mikro, Kecil, dan Menengah (UMKM) merupakan salah satu bagian yang tidak dapat dipisahkan dari dunia usaha nasional. Keberadaan UMKM menjadi suatu hal yang cukup vital dalam meningkatkan perekonomian masyarakat Indonesia di berbagai daerah. Penelitian ini bertujuan menganalisis strategi pengembangan UMKM kerajinan tangan Kiso “Jago Abadi”di Desa Kemiri, Kabupaten Banyumas. Penelitian ini menggunakan metode penelitian kualitatif yang melibatkan pelaku sebagai pengabdi dalam subjek penelitiannya, kemudian secara partisipatoris mengidentifikasi persoalan dan merancang model pemberdayaan untuk pengembangan dalam bentuk program kerja yang bisa dilakukan. Strategi yang diterapkan adalah merancang program-program yang dibutuhkan bagi UMKM sebagai modal penguatan dan pengetahuan bagi pelaku UMKM yang ikut terlibat didalamya. Cara yang dapat diterapkan yaitu dengan terus mengembangkan keunikan produk kerajinan, memperluas jangkauan pasar, selalu menjaga dan meningkatkan kualitas produk, serta konsisten melakukan promosi dan menjaga kelangsungan produksi kerajinan tangan Kiso "Jago Abadi". Hasil dari pengabdian ini yaitu ditemukannya hasil yang lebih maksimal dan efisien dalam proses produksi dan pemasaran kerajinan tangan Kiso "Jago Abadi". Strategi pengembangan potensi usaha mikro, kecil, dan menengah kerajinan tangan Kiso "Jago Abadi”di desa Kemiri, kabupaten Banyumas dapat mencapai hasil yang lebih maksimal.
\end{abstract}

Kata Kunci: Strategi, Pengembangan, UMKM, Kiso "Jago Abadi”

Copyright (C) 2021, Muflih Nurriza Pahlawi, Abu Dharin.

This is an open access article under the CC-BY NC-SA license.

http:// DOI 10.30656/ps2pm.v3i2.3902 


\section{PENDAHULUAN}

Industri kecil menengah mempunyai kedudukan dan potensi yang cukup besar dalam melakukan perbaikan ekonomi masyarakat. Usaha Mikro, Kecil, dan Menengah (UMKM) menjadi salah satu penopang perekonomian rakyat terbesar yang cukup tangguh dalam setiap kondisi.

Industri Usaha Mikro, Kecil, dan Menengah (UMKM) menjadi potensi usaha yang mampu memberikan lapangan pekerjaan sehingga dapat menyerap banyak tenaga kerja serta dapat meningkatkan pendapatan bagi masyarakat. UMKM mempunyai peran yang cukup penting dalam peningkatan dan pemerataan pendapatan masyarakat, serta ikut mendorong pertumbuhan ekonomi yang dapat mewujudkan stabilitas nasional. (Djabbar \& Baso, 2019).

UMKM menjadi elemen yang begitu penting dalam memajukan bangsa karena merupakan salah satu potensi usaha yang dapat meningkatkan kualitas dan taraf hidup masyarakat. (Ulza et al., 2018).

UMKM berperan sangat besar dalam menyerap tenaga kerja, mengurangi angka kemiskinan, dan memfasilitasi peningkatan pendapatan negara dari segi ekspor (Febriantoro, 2018). Eksistensi UMKM telah tersebar di seluruh wilayah Indonesia dengan berbagai usaha yang sangat bermacam-macam, salah satunya yaitu usaha produksi kerajinan tangan Kiso "Jago Abadi" di desa Kemiri, Kabupaten Banyumas.

Oleh karena hal itu, maka pengembangan usaha menjadi hal yang wajib dilakukan secara konsisten dan berkelanjutan dengan berbagai macam strategi yang dirancang secara matang sehingga keberadaan Kiso "Jago Abadi" tetap eksis dalam meningkatkan perekonomian dan kesejahteraan masyarakat desa Kemiri. Selain itu, UMKM juga dapat memberikan banyak lapangan pekerjaan dan menjaring masyarakat 
lebih banyak dibandingkan sektor usaha lainnya. Karenanya, kontribusi UMKM dianggap sebagai faktor penting dalam perdagangan (Saputro, 2016).

Desa Kemiri terletak di wilayah Kecamatan Sumpiuh, Kabupaten Banyumas dengan jumlah total penduduk sebanyak 5.768 jiwa. Selain terkenal sebagai desa pertanian, desa Kemiri juga memiliki beberapa hasil kerajinan tangan salah satunya yaitu usaha kerajinan tangan Kiso "Jago Abadi". Kiso atau dalam bahasa jawa disebut kepek merupakan tas atau tempat jago.

Kumpulan pengrajin Kiso "Jago Abadi" merupakan sentra pembuatan kerajinan tangan yang terletak di Desa Kemiri, Kecamatan Sumpiuh Kabupaten Banyumas yang diketuai oleh ibu Warti. Hasil kerajinan yang telah diproduksi dikumpulkan kepada tengkulak. Masih terdapat beberapa kendala yang perlu diatasi, salah satunya dari segi pemasaran.
Permasalahan lainnya yang perlu diatasi adalah keterbatasan waktu yang dimiliki para penggiat kerajinan tangan Kiso "Jago Abadi" karena mayoritasnya memiliki pekerjaan utama sebagai petani dan menjadikan usaha kerajinan kiso sebagai pekerjaan sampingan sehingga kerap tidak mampu memenuhi permintaan pasar. Oleh karena itu perlu adanya strategi dan konsep dalam rangka pengembangan Usaha kerajinan tangan Kiso "Jago Abadi" yang dapat meningkatkan kesejahteraan masyarakat di wilayah desa Kemiri.

Pengembangan merupakan usaha yang dilakukan dalam meningkatkan kemampuan konseptual, teoritis, teknis, dan moral individu atau kelompok sesuai dengan kebutuhan pekerjaan melalui pelatihan dan pendidikan (Alyas \& Rakib, 2017). Pengembangan UMKM dirasa sangat tepat dan efektif untuk menggerakkan roda perekonomian nasional. Hal ini dibuktikan karena 
kegiatan usaha dari sektor UMKM mencakup hampir semua sektor sehingga kontribusi UMKM menjadi sangat besar dan vital dalam meningkatkan pendapatan masyarakat.

Kendala yang dihadapi para pengrajin Kiso "Jago Abadi" desa Kemiri dalam hal peningkatan kualitas usaha sangat kompleks dan meliputi berbagai unsur dimana antara satu dengan lainnya saling berhubungan seperti kurangnya kemampuan manajerial, serta terbatasnya ilmu pemasaran yang hanya dilakukan kepada para tengkulak.

\section{Dalam perkembangannya,} Usaha Mikro, Kecil, dan Menengah masih belum mampu menjalankan beberapa peran dan fungsinya hingga maksimal. Terdapat hambatan yang dihadapi seperti keterbatasan modal usaha, pemilihan bahan baku, teknik pemasaran, manajemen serta minimnya penggunaan teknologi (Adhitama, 2018). Pengembangan
UMKM mempunyai peran yang cukup penting dalam pengembangan industri manufaktur. Pengembangan UMKM akan menjadi solusi dari masalah angka pengangguran yang cukup tinggi di Indonesia khususnya desa Kemiri sehingga dapat menambah lapangan kerja dan kesempatan usaha yang dapat mendorong pembangunan di daerah dan kawasan perdesaan.

Artikel ini disusun untuk membantu mencari solusi dari permasalahan terkait strategi pengembangan potensi Usaha Mikro, Kecil, dan Menengah kerajinan tangan Kiso "Jago Abadi" di desa Kemiri, kabupaten Banyumas. Penelitian ini menggunakan bentuk teknik SWOT.

Data dalam pengabdian ini dikelompokkan menjadi dua yaitu primer dan sekunder. Data primer yaitu data yang diperoleh dari keterangan narasumber, berupa wawancara. Sedangkan, data sekunder yaitu data yang diperoleh dari kepustakaan, buku, jurnal ilmiah 
dan dokumen tertulis lainnya yang relevan dengan penelitian ini (Imaniar \& Wahyudiono, 2019).

\section{METODE PELAKSANAAN}

$$
\text { Pengabdian kepada }
$$

masyarakat ini saya lakukan di desa Kemiri, Kecamatan Sumpiuh, Kabupaten Banyumas yang dilaksanakan mulai dari tanggal 15 Juli sampai 28 Agustus 2021.

Pembuatan kerajinan tangan Kiso "Jago Abadi" dimulai dengan tahap persiapan, pembelian bahan dasar produksi, pembuatan kiso, penyelesaian akhir, dan pengumpulan kepada tengkulak.

Tahap persiapan dilakukan dengan melakukan analisis berdasarkan wawancara kepada ketua kelompok kerajinan tangan Kiso "Jago Abadi" dan beberapa anggota untuk mencari data-data yang diperlukan.

Pembelian bahan dasar produksi peneliti dan pengrajin membeli di Pasar Sumpiuh yang lokasinya tidak terlalu jauh dari tempat penelitian kurang lebih $1.5 \mathrm{~km}$. Dalam proses pembuatan kiso peneliti ikut terlibat mulai dari tahap awal seperti pembelian bahan dasar produksi, proses produksi sampai tahap akhir seperti merapihkan sisa kulit bambu dengan plastik lasio sampai penjualan kepada tengkulak.

Metode penelitian dalam artikel ini menggunakan metode deskriptif dengan studi kasus pembuatan Kiso atau tas Jago di desa Kemiri Kecamatan Sumpiuh Kabupaten Banyumas. Metode penelitian deskriptif sebagaimana disampaikan oleh Sukmadinata adalah suatu metode yang berusaha untuk mendeskripsikan dan mengartikan sesuatu misalnya kondisi atau hubungan yang ada, pendapat yang berkembang, proses yang sedang berlangsung, dampak yang terjadi atau kecenderungan yang sedang berlangsung dengan menggunakan prosedur ilmiah untuk menjawab masalah secara aktual. 
Deskriptif yang dilakukan adalah deskriptif kualitatif yaitu data berbentuk kata-kata, catatan observasi, dokumentasi atau pernyataanpernyataan verbal sebagai hasil wawancara.

Pengumpulan data dilakukan melalui observasi, wawancara dan dokumentasi. Adapun penjelasan dari ketiganya yaitu:

(a) Observasi, yaitu melakukan kegiatan pengamatan langsung untuk memperoleh informasi terkini, seperti proses pembuatan kerajinan tangan Kiso dari pembelian bahan dasar sampai tahap akhir. Kemudian hasil observasi ditulis dan didokumentasikan.

(b) Wawancara adalah komunikasi dua arah untuk memperoleh data dari narasumber berupa informasi dan keterangan terhadap fokus penelitian. Wawancara ini dilakukan dengan ketua kelompok Pengrajin Kiso "Jago Abadi" dan salah satu pengrajin Kiso guna mendapatkan informasi secara lebih jelas dan mendalam.

(c) Penelurusan dokumentasi, yaitu memperoleh data tertulis seperti dokumen kegiatan, keadaaan sarana dan prasarana, dan proses produksi pembuatan kengrajinan Kiso di Desa Kemiri.

Metode analisis data dilakukan secara kualitatif, yaitu model interaktif Milles dan Hubberman yang terdiri dari 3 tahap, yaitu tahap reduksi data, pengujian data, serta penarikan kesimpulan dan verifikasi.

\section{HASIL DAN PEMBAHASAN}

Kelompok pengrajin Kiso "Jago Abadi" Desa Kemiri adalah suatu organisasi masyarakat dalam bidang kerajinan tangan Kiso atau Kepek dalam Bahasa Jawa yang lokasinya berada di desa Kemiri, Kecamatan Sumpiuh, Kabupaten Banyumas, Jawa Tengah. Kiso atau kepek adalah kerajinan tangan yang berfungsi untuk tempat atau tas jago. 
Berawal dari inisiatif salah satu pengrajin untuk membuat perkumpulan pengrajin Kiso atau Kepek di Desa Kemiri kemudian dibentuklah Kelompok pengrajin Kiso dengan nama "Jago Abadi". Kelompok ini dibentuk pada bulan Desember 2019 dengan jumlah anggota 10 orang yang keseluruhannya merupakan ibu rumah tangga.

Pertemuan anggota diadakan setiap satu bulan sekali di rumah anggota secara bergantian dan setiap anggota diwajibkan membayar kas bulanan sebesar Rp. 5.000.

Pada awal Tahun 2020 kelompok pengrajin Kiso "Jago Abadi" mendapat bantuan dari Dinas Sosial berupa uang sebesar Rp. 20.000.000.

Dari wawancara yang dilakukan kepada salah satu pengrajin Kiso yaitu Ibu Surip pada tanggal 12 Agustus 2021 didapatkan data terkait waktu produksi, modal, harga jual, bahan, dan tahapan dalam produksi Kiso atau Kepek Fiber.
Proses produksi sampai tahap akhir kurang lebih membutuhkan waktu dua hari. Modal pembuatan Kiso sebesar Rp. 25.000. penjualan produk untuk Kiso polos dihargai Rp. 55.000, sedangkan Kiso bermotif dihargai Rp. 80.000. Bahan yang digunakan yaitu Fiber, Bambu, Kawat, Selang tebal, Figura, Lasio, Tang, Gunting, Paku, Pisau, Paku, dan Pembatas Fiber.

Produksi dimulai dengan ngirati, yaitu memotong bambu menjadi bagian kecil-kecil untuk diambil kulitnya. Dari proses ngirati ini akan menghasilkan ayaran, yaitu potongan kulit bambu kecil.

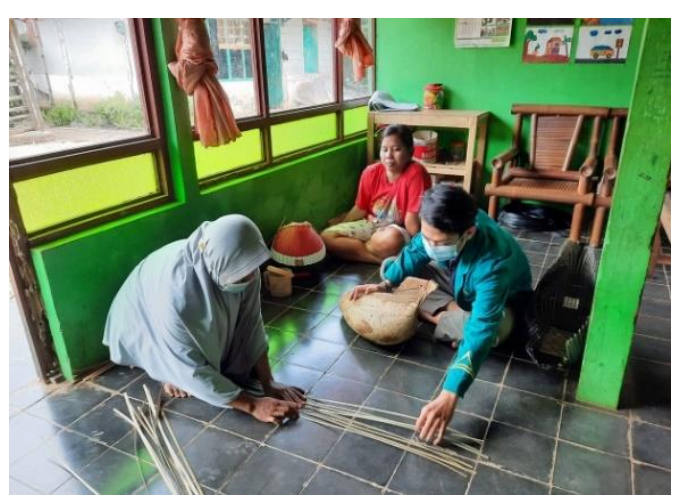

\section{Gambar 1. Ayaran bambu yang telah siap digunakan.}

Kemudian ayaran kulit bambu dipasang pada bagian bawah cetakan dan dipaku bersamaan dengan pemasangan figura. 


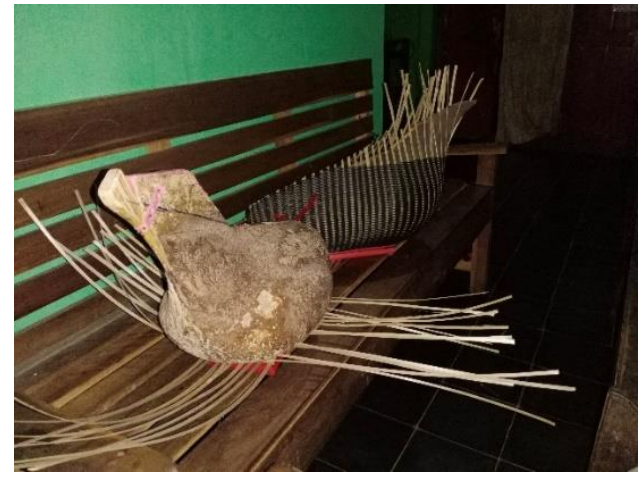

Gambar 2. Hasil ayaran bambu dan figura yang sudah terpasang pada cetakan.

Setelah ayaran dan figura terpasang pada cetakan. Langkah selanjutnya yaitu memasang fiber secara zig-zag mengikuti ayaran pada cetakan. Proses inilah yang memakan waktu paling lama dalam proses produksi. Pengrajin harus memastikan hasil anyaman rapi dan terpasang kuat. Terlebih jika membuat Kiso bermotif, waktu yang dibutuhkan lebih lama. Dalam proses ini, pengrajin juga menggunakan alat bantu berupa pembatas fiber untuk memudahkan produksi sehingga fiber tetap menempel pada cetakan. Pembatas fiber biasanya memakai selang yang dipaku.

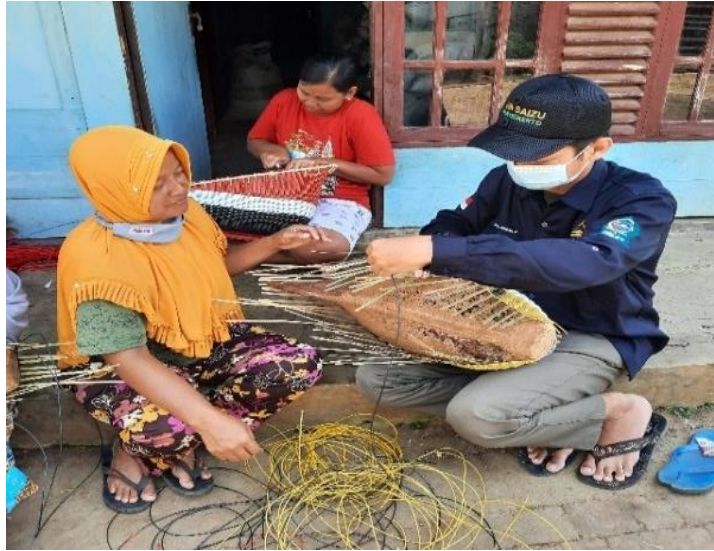

\section{Gambar 3. Proses menganyam fiber pada cetakan.}

Setelah fiber terpasang sempurna, kemudian Kiso yang telah terbentuk dilepas dari cetakan. Langkah selanjutnya adalah memasang blengker. Blengker yaitu proses merapihkan ujung anyaman fiber menggunakan kulit bambu.

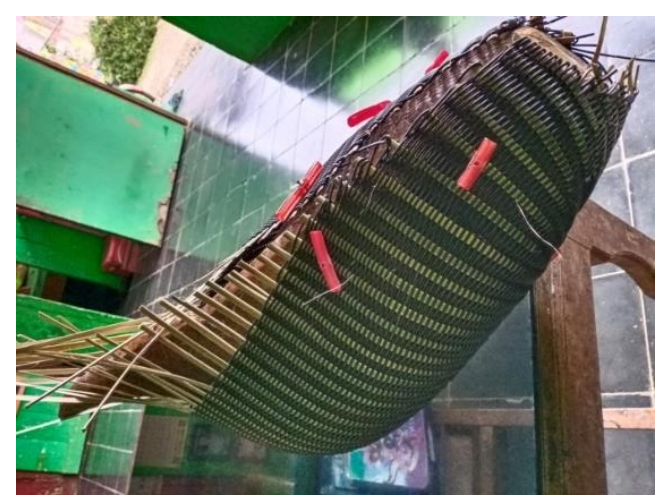

Gambar 4. Hasil anyaman fiber yang masih menempel pada cetakan.

Kemudian langkah selanjutnya adalah di tutus. Nutus atau proses penutusan yaitu menutup blengker menggunakan bahan plastik lasio. 


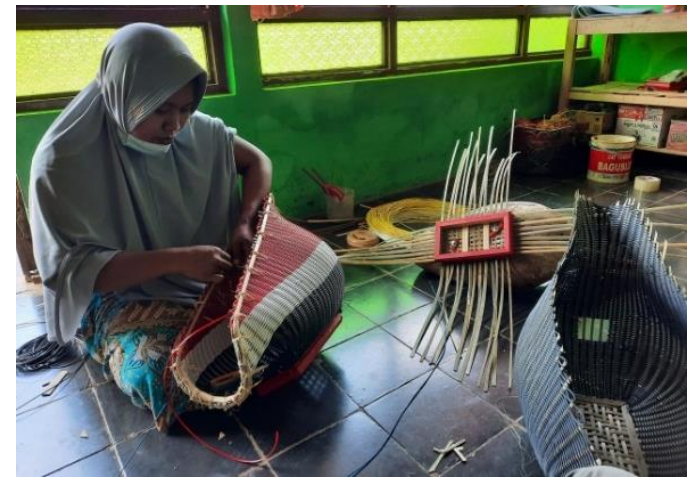

\section{Gambar 5. Proses penutusan.}

Langkah terakhir adalah garani yaitu memberi pegangan menggunakan kawat tebal dan ditutup dengan selang. Pemasangan kawat harus kuat.

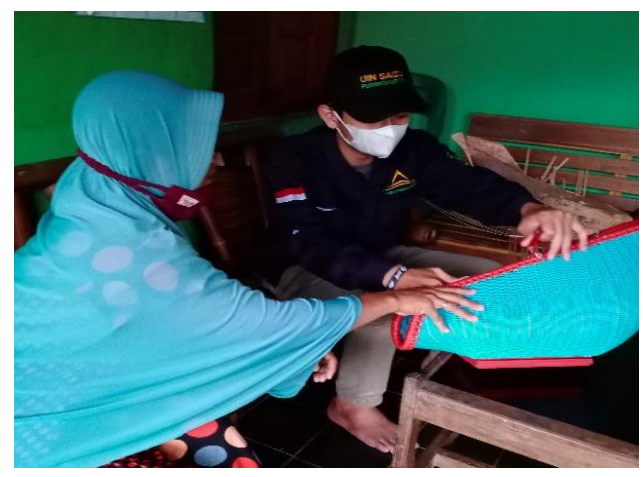

\section{Gambar 6. Kiso yang sudah selesai produksi.}

Berdasarkan wawancara yang telah dilakukan terhadap ketua kelompok usaha kerajinan tangan Kiso "Jago Abadi" Desa Kemiri yaitu Ibu Warti pada tanggal 21 Agustus 2021, ada beberapa permasalahan yang menjadi hambatan dalam mengembangkan UMKM antara lain, kurangnya pelaku usaha yang berperan aktif dalam mengembangkan UMKM, serta keterbatasan anggota yang menguasai cara pembuatan kerajinan dari tahap awal sampai akhir.

Selain itu, kendala lain yaitu adanya keterbatasan modal serta minimnya pengetahuan pengrajin tentang sistem pemasaran dan tidak adanya kontribusi dari pemerintah desa Kemiri dalam pengembangan UMKM menjadi faktor lain yang menghambat penjualan produk hasil usaha. Pemasaran hanya melalui pengepul yang mengambil hasil kerajinan satu bulan sekali sehingga kurang efektif dan efisien.

Dari permasalahan diatas, dapat disimpulkan bahwa usaha kelompok kerajinan tangan Kiso "Jago Abadi" mempunyai beberapa masalah yang dapat menghambat dalam pengembangan UMKM. Maka dari itu, kelompok kerajinan tangan Kiso "Jago Abadi" harus mempunyai daya saing dan kualitas yang tinggi. Salah satu solusi yang dapat dilakukan adalah dengan menciptakan strategi untuk pengembangan UMKM agar pengelolaannya dapat berjalan lebih terstruktur sehingga di lingkup internal dan eksternal akan lebih berkembang.

\section{Pengembangan}

UMKM merupakan langkah yang dinilai mempunyai kontribusi besar dalam 
mengembangkan

industri

manufaktur. Pengembangan UMKM mampu membantu mengatasi masalah angka pengangguran yang cukup tinggi sehingga dapat memberikan lapangan pekerjaan dan kesempatan usaha dimana hal ini dapat mendorong pembangunan di wailayah pedesaan.

Hal ini berkaitan dengan pemberdayaan masyarakat. Dimana pemberdayaan adalah konsep yang muncul sebagai sebuah strategi dalam pembangunan dari aspek penggalian potensi diri dan lingkungan untuk dimanfaatkan dalam mewujudkan peningkatan kualitas hidup manusia menjadi lebih baik. (Warto \& Sriyanto, 2021).

Tujuan pemberdayaan masyarakat adalah mendorong terciptanya kekuatan di lingkungan masyarakat sehingga mampu mengendalikan dan mengelola dirinya sendiri berdasarkan kebutuhan secara mandiri, serta mempunyai bekal menghadapi tantangan dimasa yang akan datang (Nurhidayah, 2017).

Penggunaan analisis SWOT dapat membantu pengembangan kerajinan tangan yang akan diproduksi oleh para pengrajin Kiso, mulai persiapan, proses pembuatan, dan pemasaran produk. Dengan begitu, kerajinan yang dihasilkan dapat lebih menarik minat konsumen yang diimbangi dengan pemasaran produk secara memadai.

Analisis SWOT merupakan analisis berbagai faktor secara terstruktur guna merumuskan strategi dari suatu lembaga dalam hal ini adalah produksi Kiso "Jago Abadi". Terdapat beberapa hal yang harus diperhatikan dalam mengembangkan hasil usaha melalui analisis SWOT yaitu:

1. Strength (Kelebihan atau Kekuatan)

a. Produk kerajinan tangan "Jago Abadi" mempunyai banyak peminat

b. Bahan yang digunakan fiber sehingga produk tidak mudah rusak

c. Produk kerajinan tangan "Jago Abadi" menyesuaikan pesanan mulai polos dan motif

d. Produk Kiso Fiber mempunyai kualitas yang baik karena merupakan produk kerajinan tangan

e. Harga Kiso cukup terjangkau

2. Weakness (Kelemahan)

a. Kurangnya pelaku usaha yang berperan aktif dalam mengembangkan UMKM

b. Keterbatasan anggota yang menguasai cara pembuatan kerajinan dari tahap awal sampai akhir 
c. Keterbatasan pengetahuan tentang sistem pemasaran yang sesuai

d. Tidak adanya kontribusi dari pemerintah desa Kemiri dalam membantu pengembangan UMKM

e. Tidak ada promosi melalui media sosial

f. Penjualan hanya melalui pengepul

3. Opportunity (Kesempatan)

a. Potensi pasar yang cukup menjanjikan

b. Masih banyak masyarakat sekitar yang belum memiliki pekerjaan

c. Pengguna media sosial yang sangat banyak

4. Threat (Ancaman)

a. Terdapat beberapa produk serupa sebagai pesaing di pasaran dan lebih kompetitif

b. Banyak produk serupa yang lebih mahir melakukan promosi di media sosial

Berdasarkan analisis SWOT yang telah dijelaskan di atas, penulis menggagas beberapa strategi yang dapat diterapkan dalam mengembangkan kerajinan tangan Kiso "Jago Abadi".

Pertama dari strategi S-O yaitu terus mengembangkan keunikan produk dengan menyesuaikan selera pasar, permintaan konsumen, dan memaksimalkan media sosial sebagai alat bantu dalam melakukan promosi dan memperluas jangkauan pasar.

Kedua strategi W-O yaitu melakukan survei pasar sehingga tepat dalam menyasar konsumen yang dituju dan membaca selera konsumen untuk produk kerajinan tangan "Jago Abadi", mulai dari Kiso bermotif atau polos. Kalau bermotif menggunakan motif yang seperti apa dan sebagainya. Selain itu meningkatkan produksi dengan menambah waktu produksi tidak hanya saat luang saja, serta memaksimalkan peran teknologi untuk membantu proses produksi atau pembelian bahan dasar produksi.

Ketiga strategi S-T yaitu meningkatkan kualitas produk sehingga memiliki daya saing lebih di pasaran, serta menarik minat masyarakat untuk menekuninya karena akan mempunyai potensi yang besar jika ditekuni dengan sungguhsungguh.

Keempat, strategi W-T yaitu konsisten dalam melakukan promosi serta menjaga kelangsungan produksi kerajinan tangan "Jago Abadi".

\section{SIMPULAN}

Produksi Kiso "Jago Abadi" harus memiliki daya saing dan 
kualitas yang unggul atau paling tidak mempunyai keunikan dibanding produk lain sehingga produk yang dihasilkan dapat menarik minat pembeli baik dari segi kualitas maupun keunikan.

Perlu adanya inovasi produk secara terus menerus untuk pengembangan UMKM sehingga akan menyelesaikan setiap permasalahan yang dihadapi, dan menghasilkan produk yang lebih berkualitas sehingga akan diiringi dengan peningkatan pendapatan pengrajin.

Salah satu strategi yang cocok untuk diterapkan yaitu dengan merancang berbagai program yang dibutuhkan sebagai pengembangan UMKM.

Cara yang dapat diterapkan yaitu dengan terus berinovasi dan bereksperimen untuk menghasilkan produk yang baru dan unik, memperluas jangkauan pasar, meningkatkan kualitas produk, rutin melakukan promosi dan ditingkatkan melalui media sosial serta menjaga kelangsungan produksi kerajinan tangan Kiso atau Kepek "Jago Abadi".

\section{UCAPAN TERIMAKASIH}

Penyusunan jurnal tidak akan terlaksana dengan baik tanpa adanya kerjasama dari Dosen Pembimbing Lapangan, Kelompok pengrajin Kiso Desa Kemiri, dan berbagai pihak yang telah mendukung kegiatan ini, karena itulah peneliti sampaikan banyak terimakasih kepada :

1. Allah subhanahu wata'ala yang telah memberikan kesehatan, kesempatan, dan kelancaran dalam penyusunan jurnal ini.

2. Dr. Mohammad Roqib, M.Ag. selaku Rektor UIN Prof. KH. Saifuddin Zuhri Purwokerto Purwokerto.

3. Jajaran Lembaga Penelitian dan Pengabdian Kepada Masyarakat (LPPM) UIN Prof. KH. Saifuddin Zuhri Purwokerto yang telah memberi kesempatan pada penulis untuk melakukan Pengabdian Masyarakat di Desa Kemiri sehingga seluruh rangkaian kegiatan dapat terlaksana dengan baik

4. Ibu Warti, selaku Ketua Kelompok pengrajin Kiso Desa Kemiri yang telah bersedia untuk diwawancarai dan memberi data yang diperlukan kepada penulis.

5. Ibu Surip, selaku pengrajin Kiso yang telah menyempatkan waktunya dan bersedia diwawancarai dan memberi penjelasan kepada penulis.

\section{REFERENSI}

Adhitama, M. R. (2018). Strategi Pengembangan Sentra UMKM 
Ikan Pindang di Desa Tasikagung Kabupaten Rembang. Economics Development Analysis Journal, 7(2), 204.

Alyas, \& Rakib, M. (2017). Strategi Pengembangan Usaha Mikro, Kecil, dan Menengah dalam Penguatan Ekonomi Kerakyatan (Studi Kasus pada Usaha Roti Maros di Kabupaten Maros). Sosiohumaniora, 19(2), 115.

Djabbar, I., \& Baso, S. (2019). Pengembangan Usaha Kecil \& Menengah ( UKM ) Berbasis Kinerja Di Kabupaten Kolaka Utara. Jurnal Ilmu Administrasi Publik, 7(2), 118.

Febriantoro, W. (2018). Kajian dan

Strategi Pendukung

Pengembangan E-Commerce bagi UMKM di Indonesia. Jurnal Manajerial, 3(5), 2.

Imaniar, D., \& Wahyudiono, A. (2019).

Strategi Pemerintahan

Kabupaten Banyuwangi dalam Meningkatkan Industri Pariwisata Melalui UMKM. Jurnal Reformasi, 9(2), 92.

Nurhidayah, P. (2017). Pemberdayaan Masyarakat Melalui Bank Sampah di Dusun Serut, Desa Palbapang, Kecamatan Bantul, Kabupaten Bantul. Jurnal Pemberdayaan Masyarakat, 15(2), 4.

Saputro, O. D. (2016). Pemberdayaan Masyarakat Melalui Usaha Kecil dan Menengah ( UKM ) Studi Kasus di Sentra Industri Tepung
Tapioka Desa Pogalan , Kecamatan Pogalan, Kabupaten Trenggalek. J+ Plus Inesa, 5(1), 3.

Ulza, E., Ferdiansyah, \& Masri, D. (2018). Pemberdayaan Masyarakat Melalui Pembinaan dan Bantuan Modal Usaha di Utan Kayu Jakarta Timur. Jurnal Syukur, $\quad 01(1), \quad 67$. https://doi.org/10.22236/syukur

Warto, \& Sriyanto, A. (2021). Pemberdayaan Masyarakat Melalui Pemanfaatan Lidi Kelapa di Desa Grogolpenatus Kecamatan Petanahan Kabupaten Kebumen. Solidaritas: Jurnal Pengabdian, 1(1), 60. 